Original Research Paper

\title{
Interactions of Aerosol Optical Depth and Cloud Parameters with Rainfall and the Validation of Satellite Based Rainfall Observations
}

\author{
${ }^{1}$ Md Monirul Islam, ${ }^{1}$ Md Mainul Islam Mamun, ${ }^{2}$ Md Zahidul Islam and ${ }^{1}$ Mumnunul Keramat \\ ${ }^{I}$ Department of Applied Physics and Electronic Engineering, University of Rajshahi, Rajshahi 6205, Bangladesh \\ ${ }^{2}$ Department of Information and Communication Engineering, Islamic University, Kushtia, Bangladesh
}

\author{
Article history \\ Received: 14-04-2016 \\ Revised: 22-08-2016 \\ Accepted: 17-06-2017 \\ Corresponding Author: \\ Md Monirul Islam \\ Department of Applied Physics \\ and Electronic Engineering, \\ University of Rajshahi, \\ Rajshahi 6205, Bangladesh \\ E-mail: rajib_apee@yahoo.com
}

\begin{abstract}
Aerosol-cloud interactions influence the global precipitation patterns that influence significantly the Earth's climate system. Anthropogenic aerosols alter the clouds and their optical properties. The present study has investigated the Aerosol Optical Depth (AOD), cloud parameters and rainfall interactions for three different monsoon periods (2008-2010) and also compared the satellite rainfall with ground based observations, by using MODIS and TRMM datasets. The highest average of AOD was in the month of June and lowest was in July for both Rajshahi and Sylhet divisions. Comparing between Rajshahi and Sylhet, Rajshahi was in the peak of aerosol contamination than Sylhet. The cloud parameters, such as COD and CER, were positively correlated with rainfall except CER in Rajshahi during the 2010 monsoon season and in Sylhet during the 2008 monsoon season. The investigation has showed complex interaction among $\mathrm{AOD}$, cloud parameters and rainfall in both regions during the study period. In addition TRMM satellite-derived rainfall has compared with ground-measured values. The result indicated that TRMM rainfall data were in good agreement with ground measurements with correlation coefficient of above 0.90 in Rajshahi.
\end{abstract}

Keywords: AOD, Rainfall, Cloud Parameters, Monsoon Season, Bangladesh

\section{Introduction}

Precipitation is one of the most important components in global hydrological and energy cycle for its impacts on Earth's climate system (Javanmard et al., 2010). Bangladeshi monsoonal rainfall is the main source of freshwater resource as about $80 \%$ of the annual rainfall over Bangladesh has received during the monsoon season. Food and water security in Bangladesh is highly sensitive to this monsoonal rainfall. Atmospheric aerosols have become a crucial factor in global climate simulations (IPCC, 2007). The spatial and temporal variations of aerosols can alter the cloud microphysical and optical properties which are examined by different studies (Ackerman et al., 2000; Kaufman et al., 2005). Direct and indirect effects of aerosols can strongly affect the environment, air quality, visibility and human health (Gunaseelan et al., 2014). In recent years, the aerosol contaminations make an anxious curiosity due to the increased loading of atmospheric pollutants associated with the fast step of industrialization and modernization especially in large cities and rural areas, among Asian monsoon countries Gunaseelan et al. (2013; Mamun et al., 2014a; Islam et al., 2015a) Dissimilarities are found in aerosol sources, transport and transformation and in their dismissal in India (Ramachandran and Cherian, 2008). The lifetimes of tropospheric aerosols become short by its gravitational settling and rain washout process which produce worry on region and seasons. In urban areas aerosol contaminations are several times greater than rural areas which are mainly produced by dust, soot and water droplets (Peterson, 1969). The aerosols are rapidly increasing over Indian subcontinent with high spatial and temporal variations (Streets et al., 2009; Islam et al., 2015b). Current research conclusions created more awareness about the potential effects of aerosol radiative forcing on the huge oscillation in the Indian monsoon rainfall and motion in recent years which has received 
more scientific consciousness as it has significant impact on agriculture and water resources (Menon et al., 2002; Ramanathan et al., 2005; Meehl et al., 2008). The studies of aerosols are very important because without understanding about aerosol properties their effect will be unknown and huge aerosols withstand in the atmosphere. So, the present study has conducted over two different regions in Bangladesh to understand the relationships among aerosols, cloud parameters and rainfall during the monsoon (JJAS) for three years.

\section{Materials and Methods}

\section{Site Description}

\section{Rajshahi}

The present study analyzes the aerosol properties and their interactions with cloud parameters and rainfall over two regions of Bangladesh viz., northwestern Rajshahi region and northeastern Sylhet region. The northwestern Rajshahi region lies between $23^{\circ} 5^{\prime}$ to $26^{\circ} 5^{\prime} \mathrm{N}$ latitude and $88^{\circ}$ to $91^{\circ} \mathrm{E}$ longitude. The region is bordered by famous Padma river on south, another famous Jamuna river on eastern part and India on north and west. It has a surface area of $34494.55 \mathrm{~km}^{2}$ with an approximate population of 33994000 in 2011 and 985 persons $/ \mathrm{km}^{2}$. The region is relatively backward, less developed, more povertystricken and non industrialized compared to other region of Bangladesh and $80 \%$ peoples are live in rural area and directly or indirectly related to agriculture. Main vegetation activities in this region are seasonal, especially in rainy season maximum of cultivated area goes under harvest. The climate is dominated by tropical monsoons which are characterized by high temperature, moderate rainfall with often excessive humidity and properly apparent seasonal variations. The mean annual temperature and rainfall in former Rajshahi division has been changed (Warrick et al., 1996). The region has hotter summers and colder winters and various climate change investigations showing an increasing trend in temperature and a decreasing trend in rainfall (Mamun et al., 2014b). The maximum mean temperature noticed is about 32 to $36^{\circ} \mathrm{C}\left(90\right.$ to $97^{\circ} \mathrm{F}$ ) during the months of April, May, June and July and the minimum temperature observed in January is about 7 to $16^{\circ} \mathrm{C}$ (45 to $\left.61^{\circ} \mathrm{F}\right)$. The highest rainfall is recorded during the months of monsoon. The annual rainfall in the district is about 1,448 millimeters. Meteorological drought is a common event in the region (Paul, 1998; Shahid and Behrawan, 2008). The area has eight droughts with extensive magnitude during the last forty years.

\section{Sylhet}

Sylhet is the northeastern division of Bangladesh. It lies between $24^{\circ} 30^{\prime} \mathrm{N}$ and $91^{\circ} 40^{\prime} \mathrm{E}$. The total area of the division is $12,635.22 \mathrm{~km}^{2}$. It has total population 9910219 with 780 persons $/ \mathrm{km}^{2}$ population density. Sylhet is considered one of the most charming and archaeologically rich regions in South Asia. Sylhet is a conventional tea growing region. It is bounded by the Meghalaya, Assam and Tripura states of India to the north, east and south, respectively; and by the Bangladesh divisions of Chittagong to the southwest and Dhaka to the west. Main rivers encompass Surma, Kushiyara, Manu etc. The physiography of Sylhet form mainly of hill soils, including a few large depressions known locally as 'Haors' (BMD, 2009). Sylhet is humid subtropical with a mainly hot and humid summer and a comparatively cool winter. The region is within the monsoon climatic zone with annual average maximum temperatures of $23^{\circ} \mathrm{C}$ (August-October) and average minimum temperature of $7^{\circ} \mathrm{C}$ (January). Approximately $80 \%$ of the annual mean rainfall of 3,334 $\mathrm{mm}$ occurs between May and September (BMD, 2009). The city is situated within the region where there are hills and basins which form one of the most typical regions in Bangladesh. Hill soil is the main physiography of Sylhet. Heavy rainfall is occurred regularly in Sylhet (Mamun et al., 2014b).

\section{Methods}

A collection of datasets and their derived properties have been used in this study coupled with ground-based rainfall data. We used MODIS data to study aerosol and cloud properties. TRMM satellite data and ground based precipitation data also used to examine the variations of precipitation and to compare the satellite precipitation data with ground based precipitation data.

The MODerate resolution Imaging Spectroradiometer (MODIS) is a remote sensor flying in two Earth Observing System (EOS) Terra and Aqua satellites (Remer et al., 2008). MODIS presents a continuous data collection which is mandatory for understanding both long- and short-term variation in the global environment. Seven of 36 channels (between 0.47 and $2.13 \mu \mathrm{m})$ are used to obtain aerosol properties over cloud and surface-shield areas (Martins et al., 2002). They are useful for collecting large statistics on the effects that aerosols have on clouds. Over Indian subcontinent, MODIS Terra and Aqua derived AODs have been validated by many investigators. Aerosol retrievals over land (Kaufman et al., 1997) from over oceans (Tanre et al., 1997) are more accurate. MODIS retrieves aerosol optical depth over vegetated land at three visible channels have high accuracy of $\pm 0.05 \pm 0.2 \tau$ (Kaufman et al., 1997; Chu et al., 2002; Levy et al., 2007). The monthly average of Aerosol Optical Depth (AOD), Cloud Optical Depth (COD), Cloud Effective Radius (CER) were derived from MODIS with level 3 Monthly MOD08_M3.051 product. 
The Tropical Rainfall Measuring Mission (TRMM) is a mutual US-Japan program to measure tropical and subtropical rainfall using Precipitation Radar (PR), TRMM Microwave Imager (TMI) and the Visible and Infrared Scanner (VIRS) instruments (Javanmard et al., 2010). TRMM was launched in 1997 into a particular orbit that enlarge observations of the tropical regions in a $\pm 40^{\circ}$ latitude band (Kummerow et al., 2000). It covers the diurnal cycle and both a passive microwave sensor (TMI) and an active microwave radar (PR) are located onboard the satellite. It originally carried five rainmeasuring instruments described in Kummerow et al. (1998). A large range of disciplines are covered by TRMM contributions, including climatology studies (rain, latent heat profiles, lightning and cloud systems along with their diurnal cycles), hydrological applications and practical use in Numerical weather Prediction centers. Many researchers have validated TRMM in various countries, e.g., Islam and Uyeda (2007) used TRMM in determining the climatic aspects of rainfall over Bangladesh, Almazroui (2010; Ud din et al., 2008) used bilinear weighted interpolation technique to validate TRMM in Kuwait, Wagner et al. (2009) used TRMM statistics in the White Volta basin, etc. Monthly TRMM_3B43.007 precipitation data products were used in this study to examine the relationship between AOD and rain rate also to examine the validity of satellite precipitation data with ground station precipitation data.

The ground station data used in this study are mostly secondary in nature and collected from six climatic stations in the northwest region of Bangladesh. Data are collected from Bangladesh Meteorological Department (BMD). BMD records rainfall, temperature and other climatic data at seven stations situated in and around the study area. The climatic data are recorded daily. The main problem of climatic data is number of missing data in the time series corrected using different averaging method. Quality controls of data are done by number of checks before analyzing. The collected data are in millimeter $(\mathrm{mm})$, converted to hourly rain rate as millimeter in hour $(\mathrm{mm} / \mathrm{hr})$. Then the data were computed to give a mean monthly and mean annual rain rate values. The continuity of the daily rainfall records was disrupted by some missing data which was checked carefully and estimated those by averaging from available data for a particular time. Unusual procedure for estimating the missing records (i.e., weighted average interpolation) was not possible because of single point consideration.

\section{Results and Discussion}

\section{Variations of $A O D$ and Rain Rate in Monsoon}

Aerosols play an important character in rainfall pattern because abnormal cooling/heating effects by aerosol conflicts the hydrological cycle and causes the severe flood/drought conditions. It depends on aerosol types and so it is essential to understand the variations and impacts of aerosols on rainfall pattern.

Table 1 shows the mean variations of aerosol and other parameters for Rajshahi and Sylhet divisions of Bangladesh. In Rajshahi, the AOD values during 2008 ranged between 0.79 and 0.23 , while the rain rate was $0.186 \mathrm{~mm} / \mathrm{h}$. For 2009, AOD values varied from 0.80 to 0.33 , while the rain rate was of $0.194 \mathrm{~mm} / \mathrm{h}$. For 2010, the AOD averages were 0.93 to 0.28 and the rain rate was $0.163 \mathrm{~mm} / \mathrm{h}$. Figure 1 shows the daily monsoon variations of $\mathrm{AOD}$ and rain rate over Rajshahi. Maximum and minimum both were noticed in 2010; in the monsoon season, the city received its highest rain rate in 2009 and lowest rain rate in 2010 and the highest AOD was found in June. The maximum of AOD in Rajshahi would be due to higher temperature, lower rainfall, dryer and arid environment and pollutions blown from neighboring states of India. Highest AOD peak was noticed in June and large number of AOD points was found in 2010 compared to the other years. The figure shows the continuous increase of aerosols in 2010 with less amount of rainfall and hence these aerosols may obstruct the rainfall. Increased aerosols and the local aerosol transmission may reduce the precipitation efficiency responsible for the precipitation contraction (Gunaseelan et al., 2014).

Table 1. Mean of AOD and other parameters for Rajshahi and Sylhet divisions in Bangladesh

\begin{tabular}{|c|c|c|c|c|c|c|}
\hline \multirow[b]{2}{*}{ Parameter } & \multicolumn{2}{|l|}{2008} & \multicolumn{2}{|l|}{2009} & \multicolumn{2}{|l|}{2010} \\
\hline & Rajshahi & Sylhet & Rajshahi & Sylhet & Rajshahi & Sylhet \\
\hline AOD & 0.520 & 0.350 & 0.580 & 0.390 & 0.540 & 0.360 \\
\hline COD & 15.200 & 15.900 & 11.990 & 13.410 & 11.540 & 13.960 \\
\hline CER & 17.220 & 17.780 & 16.550 & 16.810 & 17.210 & 17.710 \\
\hline $\mathrm{RR}(\mathrm{mm} / \mathrm{hr})$ & 0.186 & 0.325 & 0.194 & 0.287 & 0.163 & 0.439 \\
\hline
\end{tabular}

$A O D$ aerosol optical depth, $C O D$ cloud optical depth, $C E R$ cloud effective radius, $R R$ rain rate (in $\mathrm{mm} / \mathrm{hr}$ ) 


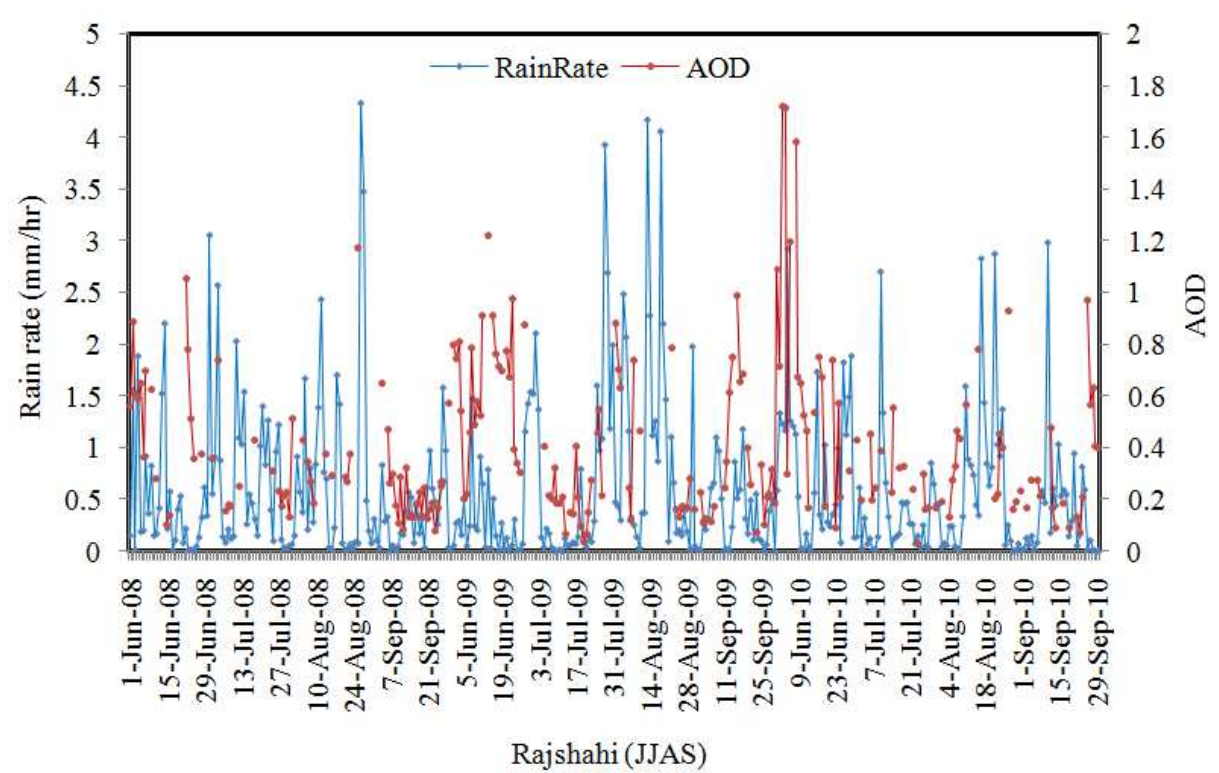

Fig. 1. Variations of daily AOD and rain rate of monsoon seasons during 2008, 2009 and 2010 over Rajshahi

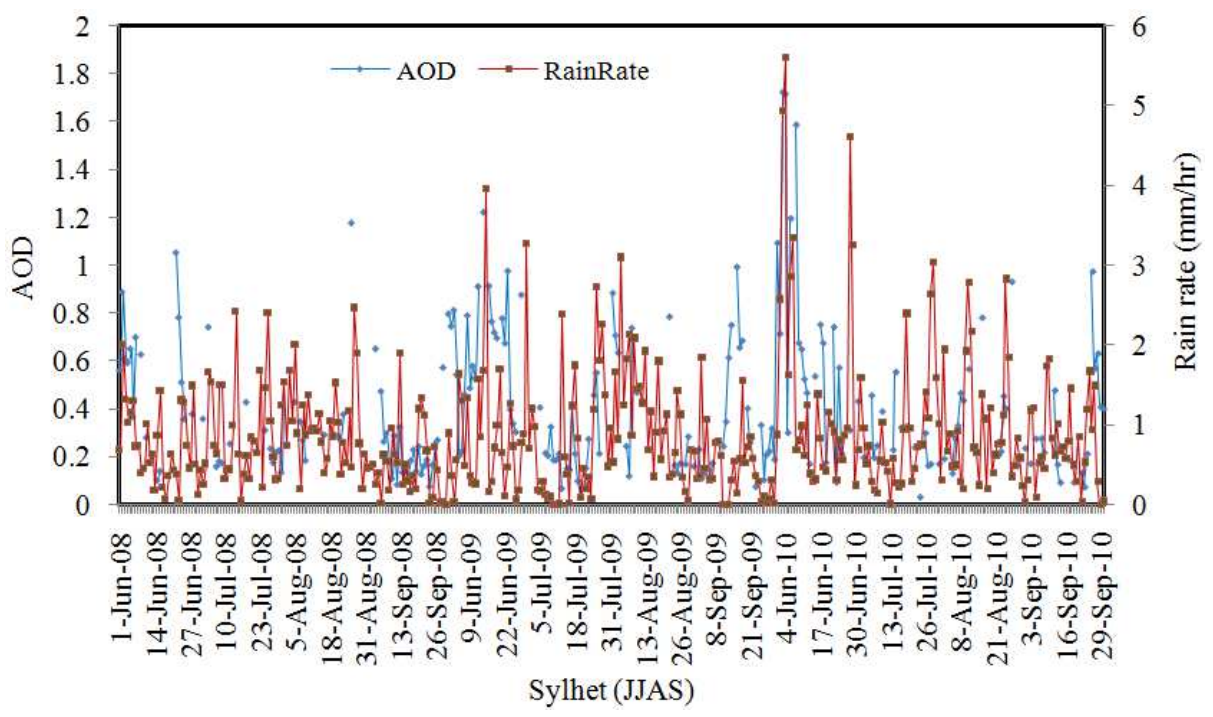

Fig. 2. Variations of daily AOD and rain rate of monsoon seasons during 2008, 2009 and 2010 over Sylhet

AOD for Sylhet ranged from 0.61 to 0.12 and the rain rate was $0.325 \mathrm{~mm} / \mathrm{h}$ during 2008; in 2009, the AOD varied from 0.66 to 0.10 and the rain rate was 0.287 $\mathrm{mm} / \mathrm{h}$; in 2010, AOD ranged between 0.64 and 0.14 and rain rate was $0.439 \mathrm{~mm} / \mathrm{h}$. Figure 2 illustrates the variations of AOD and rain rate during monsoon period over Sylhet. Maximum AOD was noticed in June 2010; in the monsoon season, the city received its highest rain rate in 2010 and lowest rain rate in 2009 and the highest AOD was found in June while the lowest AOD was obtained in July.

It was concluded that the AOD, rainfall and cloud interactions are still very complicated phenomena and not yet well understood. In this study, it resulted that the increased AOD enhances the precipitation in Rajshahi but the increase in aerosols obstructs the precipitation over Sylhet. Existences of more aerosols may produce the small cloud droplets which in turn reduces the precipitation with variation in the magnitude of cloud properties. On the other way, these smaller droplets are also less likely to collide and coalesce, which may constrain precipitation formation and thus raise cloud water and cloud fraction. This work implied that the suppression/favor of precipitation depends on the aerosol types as the hygroscopic particles are able for cloud condensation nuclei which improve formation of cloud 
with precipitation improvement. Meanwhile, hydrophobic particles are not good enough for the cloud condensation nuclei which may collapse precipitation. Meteorological parameters also play an important role in aerosol, cloud and rainfall interactions.

An increasing AOD was found over Rajshahi when a decreasing AOD was found in Sylhet during the last decade (Islam et al., 2015b). The population density in Rajshahi is higher than the Sylhet also Rajshahi is the most arid city while Sylhet has a cleaner environment than the others. Rajshahi was dominated by highest aerosol level during 2009 and lowest aerosol was in 2008; meanwhile Rajshahi received its maximum rain rate in 2009 and minimum in 2010. But in Sylhet, AOD was found to be highest in 2009 and lowest AODs were in 2008 and Sylhet also received its maximum precipitation in 2010 and minimum precipitation in 2009. Minimum AODs in Sylhet in 2008 and 2010 may be a reason for the highest rain rate pattern in those years and lowest rain rate in Sylhet during 2009 may be due to the highest AOD; these aerosols may warm-up the atmosphere which induces raise in temperatures and interfere the rainfall pattern and result as drought. This may be a potential reason for higher AOD noticed in Rajshahi during 2009 since the aerosols, desert dust and soot can be transported from one region to other. Hydrophobic aerosols do not play as good Cloud Condensation Nuclei (CCN), such as soot and dust, which may deed to suppress rainfall. The rainfall weakness will also due to a large increase in the AODs at shorter visible wavelengths. In both the divisions, the maximum AOD was in June and minimum was in July; this may due to the winds and these summer monsoon winds lifts the dust aerosol to the atmosphere from the dry land (Ganguly et al., 2006). The highest monsoon rainfall received by these divisions in July washes out the aerosol particles from the atmosphere.

\section{Aerosol, Rain Rate and Cloud Interactions over Monsoon}

Anthropogenic aerosols have an impact on cloud and meteorological parameters which also stresses the large uncertainties both in the challenging cases and the analysis of their impact. Correlation analysis was performed to understand the relationship and interactions between the aerosol, cloud and meteorological parameters with rainfall.

In Rajshahi, during 2008, as per the correlation analysis, AOD was positively correlated with COD while it was negatively correlated with CER and rain rate. In 2009, the association between aerosols and COD and rain rate was positive whereas CER was negative. During 2010, COD and rain rate related positively to aerosol and CER related negatively. Figure 3 a represents the monsoon seasonal variations of AOD and cloud parameters over Rajshahi. It shows that at the starting of each month (JJAS), the AOD was increasing and then again it decreasing in next month of July. The COD peak was noticed in 2008, but it was very low in 2009 and it moved in a random manner; however, it was in a decreasing style in 2010. In 2008 AOD increased with increased in CER and vice versa but in other years CER and AOD showed a random relation between them. During good monsoon (2008, 2009) COD and CER changed in same pattern with AOD as AOD increased with increased in COD and CER and vice versa while in bad monsoon (2010), AOD and cloud parameters showed not such a similar association among them. Figure $3 b$ shows the cloud parameters and rainfall interactions in Rajshahi division. The maximum peak of rain rate was noticed in 2009 and 2008 whereas in 2010, the rainfall was in minimum range. Throughout the study periods, CER and COD increased the rain rate tends to increase and vice versa. In this division, throughout the monsoon or maximum rain rate years 2008 and 2009, COD and CER were related similarly but the rain rate deficiency may be due to the opposite link found between COD and CER in drought or minimum rain rate year (2010). Because the COD and CER are directly related to each other, increase in CER increases the COD and this could result in more rainfall and vice versa.

In Sylhet, during 2008, the aerosols were linked positively to COD but negatively linked with CER and rain rate. In the bad monsoon year (2009), AOD connected positively with COD and negatively with CER and rain rate. In 2010, AOD related positively with $\mathrm{COD}$ and rain rate but negatively related to CER. Figure 4a represents the AOD and cloud variations of monsoon season over Sylhet. On the first month, the AOD was in increasing manner and at each month end it tends to decrease. Here, also large number of AOD points was noticed in bad monsoon year (2009) whereas the AOD highest peaks were found in June and minimum was in July. Maximum AOD was in 2009 with limited presence of the cloud effective radius and cloud optical depth but minimum AOD was in 2008 with extreme presence of the cloud effective radius and cloud optical depth. CER is regularly in increasing manner from June to July during the monsoon years. In 2009, the presence of COD is highest. During the monsoon years COD increased with increased in AOD and COD decreased with decreased in AOD. Figure $4 \mathrm{~b}$ confers the rain rate relations with cloud parameters in Sylhet over monsoon for good monsoon (2010) and bad monsoon (2009, 2008) years. Highest rain fall peak was noticed in August in 2008 and 2009 while it was in June in active monsoon year 2010. Here the AOD increased with rain rate in 2009 and 2010 monsoon periods. The COD, AOD and rain rate were in peak during June 2010, but the CER increases steadily whereas the COD, AOD and rain rate were in similar pattern with variations. CER increased steadily but COD showed a random variation 
during the monsoon years. The higher cloud effective radius in 2010 may be the reason for the higher rainfall with lower AOD in the monsoon year because the larger
CER will able to produce more size of cloud droplets and it enhances the rain. A stable increase in CER was noticed during the monsoons.

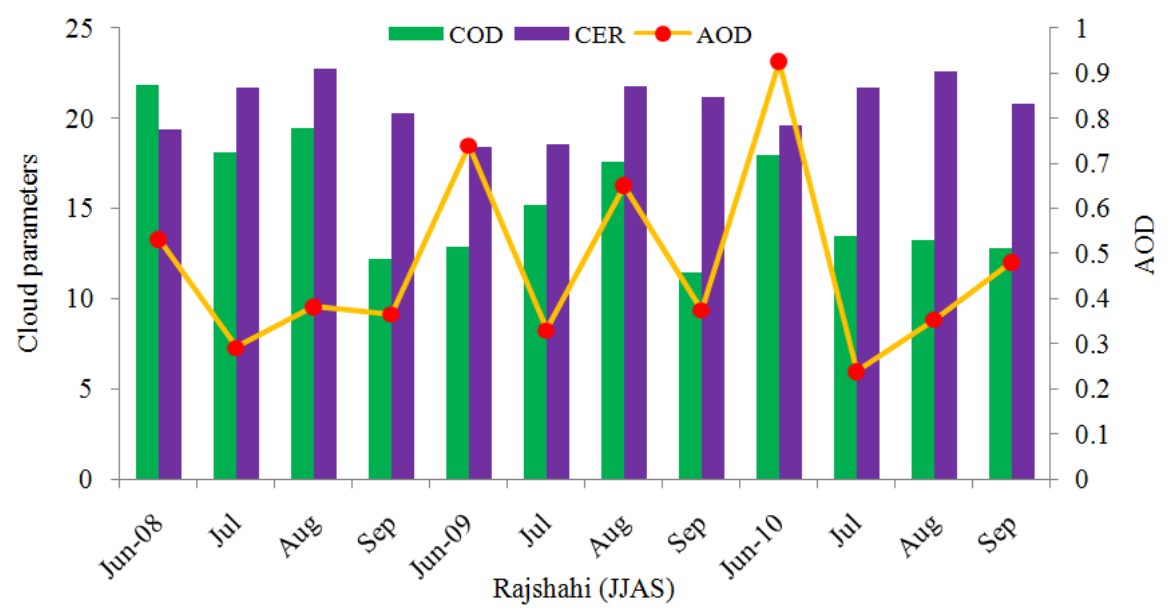

(a)

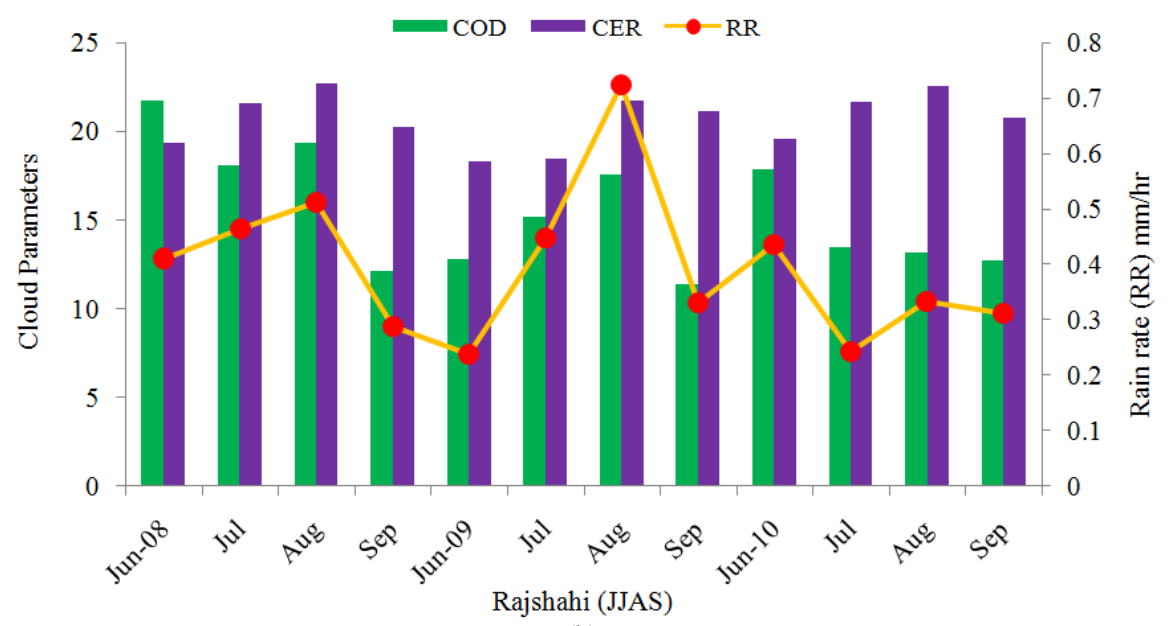

(b)

Fig. 3. Variations of cloud parameters, AOD and rainfall over Rajshahi. (a) COD, CER and AOD variations; (b) COD, CER and $R R$ variations

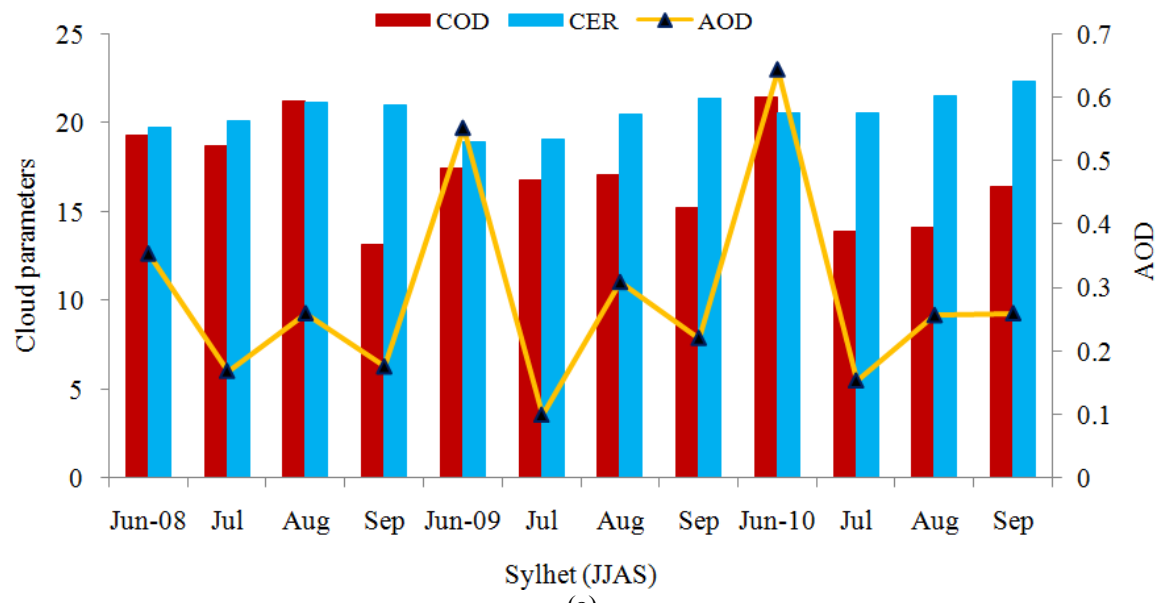

(a) 


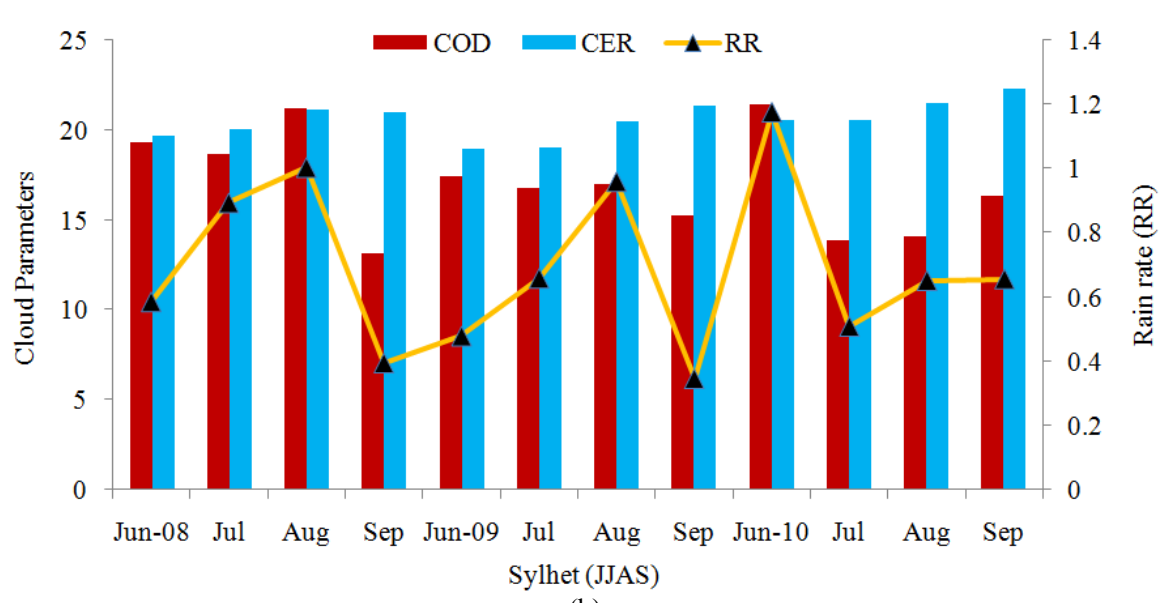

(b)

Fig. 4. Variations of cloud parameters, AOD and rainfall over Sylhet. (a) COD, CER and AOD variations; (b) COD, CER and RR variations

Hence, the cloud and meteorological parameters analysis is very important for aerosol and rainfall interaction process. In this research, some contradictory results were found between good monsoon and bad monsoon years. Apart from the atmospheric circulation systems, the higher temperatures (lower relative humidity) favor/suppress the monsoon activeness during the study periods. Rise in temperature caused boost of aerosols that effects the size distribution and appeared in higher quantity of AOD. Variations in temperature are also associated to aerosol loadings in the different seasons because the circulation shifts are connected with the monsoon system. Changes in cloud properties and temperatures may edge to increase/decrease the monsoon precipitation. Geographic locations of study area, time, aerosol types, horizontal-vertical profiles of aerosols and clouds, adiabacity, cloud spatial thickness, chemical formation, meteorological conditions and size distribution of aerosols also play a big role in the uncertainties of aerosols, rainfall and cloud properties correlation.

\section{Comparison of Satellite (TRMM) Rainfall Data with Ground-Based Data}

The research objective of this section is the comparison of TRMM rainfall data with ground-based rainfall data. Comparison of the data sets is backdated from January 2001 to December 2010 over old Rajshahi divisions. The study is limited to the monthly and annual verification of satellite temporal fields. This is accomplished using time series and statistics. The analysis to validate the TRMM in old Rajshasi division including six ground stations and also a temporal distribution comparison was done, but just for monthly and annual time series.
Figure 5 shows the monthly mean variation of rain rate of TRMM and ground station over old Rajshahi division. In that graph all of the time TRMM was overestimating the rain rate. The over estimation is bigger in the maximum rain rate months of June and July. This comparison suggests that in the TRMM retrievals capture rain occurrences somehow better during the whole months. In July the ground station estimated monthly mean rain rate was maximum and then decreasing from July, but TRMM estimated rain rate was maximum in July and then decreasing from August. Another variation was obtained in September: That in September Ground station estimated rain rate was slightly higher than August where TRMM estimated rain rate was lower than August. The correlation coefficient between TRMM and ground station monthly mean rain rate was greater than 0.90 .

Figure 6 exhibits the annual average rain rate of TRMM and ground station over old Rajshahi division from 2001 to 2010 . The result shows that the TRMM rain rate was overestimating in all the years. The highest overestimation was in 2010 and the lowest was in 2007. The correlation coefficient between TRMM and ground station annual mean rain rate was greater than 0.95 .

From these results it is seem that, TRMM rainfall agrees well with the ground station rainfall. The comparison for monthly mean and annual mean was showed a good correlation coefficient of greater than 0.9 . For rainfall events detected both by the satellite and ground station, the TRMM rainfall appears to be overestimated in magnitude, this could due to the fact that the area captured in TRMM is greater than the old Rajshahi division as it was the $25^{\circ} \times 25^{\circ}$ grid. 


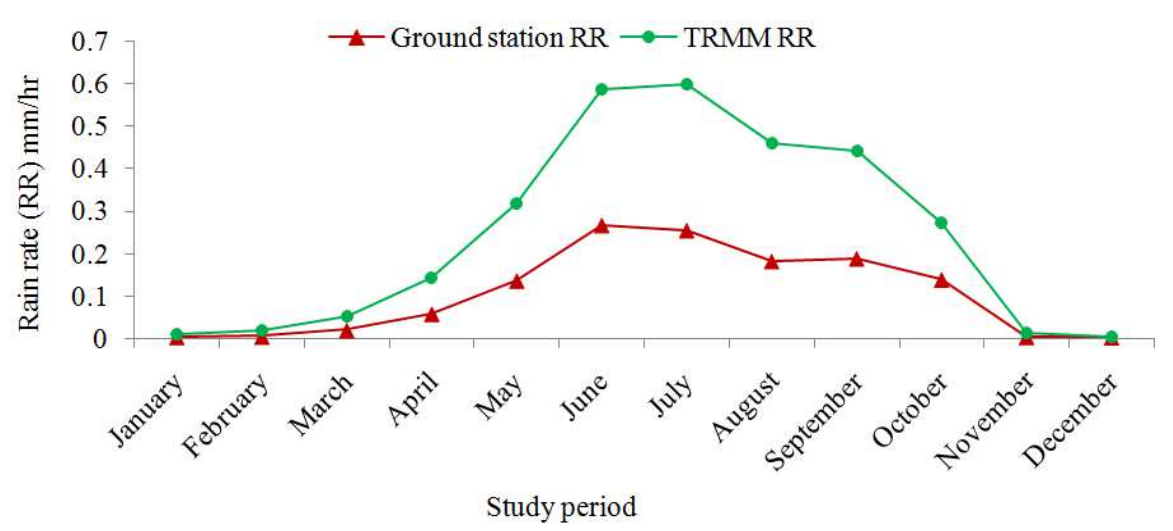

Fig. 5. Monthly mean of ground station and TRMM satellite rain rate (RR) in Rajshahi division of Bangladesh during 2001-2010

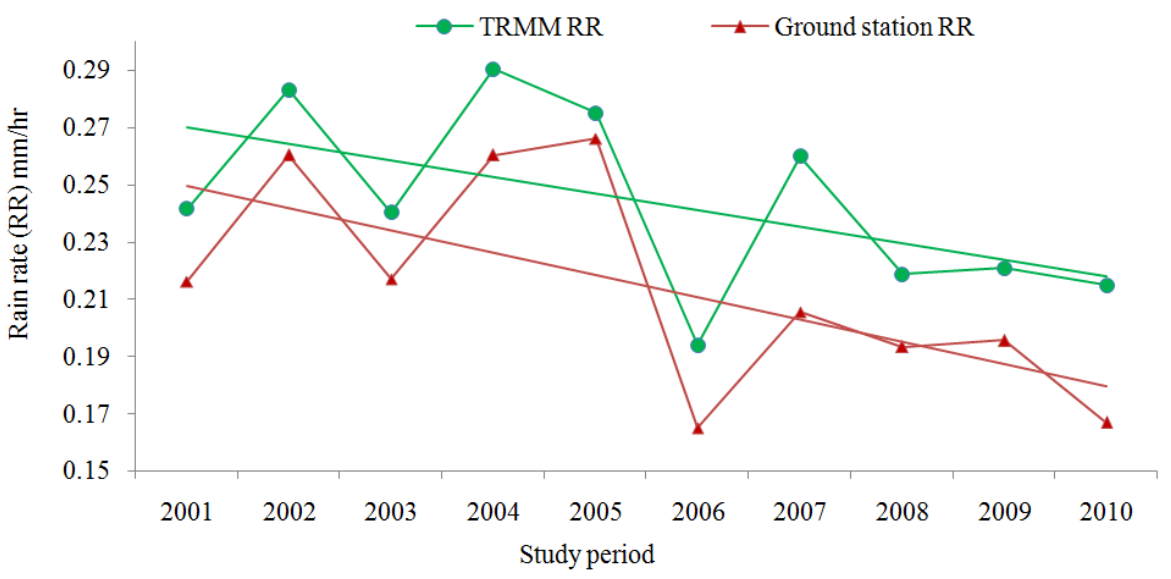

Fig. 6. Ground station and TRMM satellite Rain Rate (RR) time series variations in Rajshahi division of Bangladesh during 2001-2010

\section{Conclusion}

The results of this study were discussed about the relationships of aerosols, cloud parameters and rainfall from 2008 to 2010 for the monsoon season because Bangladesh receives its major portion of the rainfall in this season only. Aerosols naturally play a critical role in the cloud formations as well as rainfall over a particular region and particular season. Sometimes aerosols enhance the precipitation and sometimes it obstructs the precipitation. Therefore the possible impacts of aerosols on hydrological cycle are very complex as aerosols play both roles. Therefore this investigation suggests that the interaction between AODs and meteorological parameters needs to be studied in greater schedule. Monsoon seasons of 2009 in Rajshahi and 2010 in Sylhet had more rainfall than other years but COD showed positive correlation with AOD while CER showed negative correlation in all the years. As far as variations concerned, the AOD were more in weak monsoon season over Sylhet but AOD were more in active monsoon season over Rajshahi. COD and CER were showed a direct association with AOD but their relationship with rainfall is not clear in the study periods. Though the lifetimes of aerosols are quite less, its impacts will be greater. Results suggest that the interrelation between AOD and meteorological parameters needs to be examined in greater detail as information on the time for knowing the different aerosol species and their transfer rates which are yet unavailable for Bangladesh, are essential to undertake such a study. TRMM estimated rainfall and ground station measured rainfall data were used to validate satellite rainfall data over northwestern Rajshahi region in Bangladesh and two rainfall data sets follow the same pattern. On the monthly and annual mean scale the correlation of TRMM and ground measurements were always more than 0.90 . It was also realized from the comparison that there was a tendency of TRMM to overestimate during the whole study period but the overestimation was very high. Overall, the TRMM product was used in this study has shown that satellite-derived rainfall can be used to complement ground-based measurements. In cases where ground measurements 
are not available, it could be used to get an explanation of rainfall situation. Therefore in northwestern region of Bangladesh TRMM is good for rainfall analysis with application to water recourse management. The use of satellite data in Bangladesh will be of great benefit considering the difficulties in accessing data locally and from the other countries.

\section{Acknowledgment}

The authors are thankful to GES-MODIS and GESTRMM for providing the satellite datasets. The authors also gratefully acknowledged to BMD for providing ground-station precipitation data.

\section{Author's Contributions}

Md Monirul Islam: Pariticipated in all experiments, coordinated the data-analysis and contributed to the writing of the manuscript.

Md Mainul Islam Mamun: Designed the research plan and organized the study.

Md Zahidul Islam: Coordinated the mouse work

Mumnunul Keramat: Designed the research plan and organized the study. Also contributed to the writing of the manuscript.

\section{Ethics}

This article is original and contains unpublished material. The corresponding author confirms that all of the other authors have read and approved the manuscript and no ethical issues involved.

\section{References}

Ackerman, A.S., O.B. Toon, D.E. Stevens, A.J. Heymsfield and V. Ramanathan et al., 2000. Reduction of tropical cloudiness by soot. Science, 288: 1042-1047. DOI: $10.1126 /$ science.288.5468.1042

Almazroui, M., 2010. Calibration of TRMM rainfall climatology over Saudi Arabia during 1998-2009. Atmos. Res., 99: 400-414.

DOI: 10.1016/j.atmosres.2010.11.006

BMD, 2009. BMD: Official information. Bangladesh Meteorological Department, Dhaka, Bangladesh.

Chu, D., Y. Kaufman, C. Ichoku, L. Remer and D. Tanré et al., 2002. Validation of MODIS aerosol optical depth retrieval over land. Geophys. Res. Lett., 29: MOD2-1-MOD2-4. DOI: $10.1029 / 2001$ GL013205

Ganguly, D., A. Jayaraman and H. Gadhavi, 2006. Physical and optical properties of aerosols over an urban location in Western India: Seasonal variabilities. J. Geophys. Res.

DOI: 10.1029/2006JD007392
Gunaseelan, I.B., V. Bhaskar and K. Muthuchelian, 2013. The impact of aerosol optical depth impacts on rainfall in two different monsoon periods over Madurai, India. Aerosol Air Quality Res., 13: 1608-1618. DOI: 10.4209/aaqr.2012.07.0197

Gunaseelan, I.B., V. Bhaskar and K. Muthuchelian, 2014. The effect of aerosol optical depth on rainfall with reference to meteorology over metro cities in India. Environ. Sci. Pollut. Res., 21: 8188-8197. DOI 10.1007/s11356-014-2711-4

IPCC, 2007. Changes in Atmospheric Constituents and in Radiative forcing. Intergovernmental Panel on Climate Change, Cambridge University Press, New York.

Islam, N.M. and H. Uyeda, 2007. Use of TRMM in determining the climatic characteristics of rainfall over Bangladesh. Remote Sens.. Environ., 108: 264-276. DOI: 10.1016/j.rse.2006.11.011

Islam, M.M., M.M.I. Mamun, A.H. Rasel and M. Keramat, 2015a. Pattern analysis of trace gases over Bangladesh using satellite remote sensing. Int. J. Remote Sens., 36: 3979-3996. DOI: 10.1080/01431161.2015.1070318

Islam, M.M., M.M.I. Mamun, P.K. Mondol and S. Ali, 2015b. Monitoring the spatio-temporal variations of aerosols over Bangladesh. IOSR J. Applied Phys., 7: 18-29. DOI: 10.9790/4861-07321829

Javanmard, S., A. Yatagai, M.I. Nodzu, J. Bodaghjamali and $\mathrm{H}$. Kawamoto, 2010. Comparing high-resolution gridded precipitation data with satellite rainfall estimates of TRMM 3B42 over Iran. Adv. Geosci., 25: 119-125. DOI: 10.5194/adgeo-25-119-2010

Kaufman, Y., D. Tanré, L. Remer, E. Vermote and A. Chu et al., 1997. Operational remote sensing of tropospheric aerosol over land from EOS moderate resolution imaging spectroradiometer. J. Geophys. Res., 102: 17051-17067. DOI: 10.1029/96JD03988

Kaufman, Y.J., I. Koren, L.A. Remer, D. Rosenfeld and Y. Rudich, 2005. The effect of smoke, dust and pollution aerosol on shallow cloud development over the Atlantic Ocean. Proc. Nat. Acad. Sci. USA, 102: 11207-11212. DOI: 10.1073/pnas.0505191102

Kummerow, C., W. Barnes, T. Kozu, J. Shiue and J. Simpson, 1998. The Tropical Rainfall Measuring Mission (TRMM) sensor package. J. Atmos. Oceanic Technol., 15: 809-817. DOI: 10.1175/15200426(1998)015<0809:TTRMMT>2.0.CO;2

Kummerow, C., J. Simpson, O. Thiele, W. Barnes and A.T.C. Chang et al., 2000. The status of the Tropical Rainfall Measuring Mission (TRMM) after two years in orbit. J. Applied Meteorol., 39: 1965-1982. DOI:

$10.1175 / 1520$ 0450(2001)040<1965:TSOTTR > 2.0.CO;2

Levy, R., L. Remer, S. Mattoo, E. Vermote and Y. Kaufman, 2007. Second-generation operational algorithm: Retrieval of aerosol properties over land from inversion of Moderate Resolution Imaging Spectroradiometer spectral reflectance. J. Geophys. Res. DOI: 10.1029/2006JD007811 
Mamun, M.M. I., Islam M.M. and P.K. Mondol, 2014a. The seasonal variability of aerosol optical depth over Bangladesh based on satellite data and HYSPLIT model. Am. J. Remote Sens., 2: 20-29. DOI: $10.11648 /$ j.ajrs.20140204.11

Mamun, M.M.I., M.M. Islam, A.H. Rasel and M. Keramat, 2014b. An observational study of aerosol optical properties and their relationships with meteorological parameters over Bangladesh. J. Applied Geol. Geophys., 2: 75-84. DOI: 10.9790/0990-02617584

Martins, J., D. Tanré, L. Remer, Y. Kaufman and S. Mattoo et al., 2002. MODIS Cloud screening for remote sensing of aerosols over oceans using spatial variability. Geophys. Res. Lett., 29: MOD4-1-MOD4-4. DOI: 10.1029/2001GL013252.

Meehl, G.A., J.M. Arblaster and W.D. Collins, 2008. Effects of black carbon aerosols on the Indian monsoon. J. Climate, 21: 2869-2882. DOI: $10.1175 / 2007$ JCLI1777.1

Menon, S., J. Hansen, L. Nazarenko and Y. Luo, 2002. Climate effects of black carbon aerosols in China and India. Science, 297: 2250-2253. DOI: $10.1126 /$ science. 1075159

Paul, B.K., 1998. Coping mechanisms practised by drought victims (1994/5) in North Bengal, Bangladesh. Applied Geography, 18: 355-373. DOI: 10.1016/S0143-6228(98)00026-5

Peterson, J., 1969. The climate of cities, a survey of recent literature. National Air Pollution Control Administration, Publication.

Ramachandran, S. and R. Cherian, 2008. Regional and seasonal variations in aerosol optical characteristics and their frequency distributions over India during 2001-2005. J. Geophys. Res. DOI: 10.1029/2007JD008560

Ramanathan, V., C. Chung, D. Kim, T. Bettge and L. Buja et al., 2005. Atmospheric brown clouds: Impacts on South Asian climate and hydrological cycle. Proc. Nat. Acad. Sci. USA, 102: 5326-5333. DOI: $10.1073 /$ pnas.0500656102
Remer, L., R.G. Kleidman, R.C. Levy, Y.J. Kaufman and D. Tanre et al., 2008. An emerging aerosol climatology from the MODIS satellite sensors. J. Geophys. Res., 113: D14S01-D14S01.

Shahid, S. and H. Behrawan, 2008. Drought risk assessment in the Western part of Bangladesh. Nat. Hazards, 46: 391-413. DOI: 10.1007/s11069-007-9191-5

Streets, D.G., F. Yan, M. Chin, T. Diehl and N. Mahowald et al., 2009. Anthropogenic and natural contributions to regional trends in aerosol optical depth, 1980-2006. J. Geophys. Res. DOI: 10.1029/2008JD011624

Tanre, D., Y.J. Kaufman, M. Herman and S. Mattoo, 1997. Remote sensing of aerosol properties over oceans using the MODIS/EOS spectral radiances. J. Geophys. Res., 102: 16971-16988. DOI: 10.1029/96JD03437

Ud Din, S., A. Al-Dousari, A. Ramdan and A. Al Ghadban, 2008. Sitespecific precipitation estimate from TRMM data using bilinear weighted interpolation technique: An example from Kuwait. J. Arid Environ., 72: 1320-1328.

DOI: 10.1016/j.jaridenv.2007.12.013

Wagner, S., H. Kunstmann, A. Bardossy, C. Conrad and R.R. Colditz, 2009. Water balance estimation of a poorly gauged catchment in West Africa using dynamically downscaled meteorological fields and remote sensing information. Phys. Chem. Earth, Parts A/B/C, 34: 225-235.

DOI: $10.1016 /$ j.pce.2008.04.002

Warrick, R.A., G.J. Kenny, G.J. Sims, N.J. Ericksen and Q.K. Ahmad et al., 1996. Integrated model systems for national assessments of the effects of climate change: Applications in New Zealand and Bangladesh. Water Air Soil Pollut., 92: 215-227. 